\title{
Efeito de condicionadores químicos sobre a qualidade da cama de frango
}

\author{
[Effect of chemical conditioners on poultry litter quality] \\ M.C. Oliveira ${ }^{1}$, H.A. Ferreira ${ }^{2}$, L.C. Cancherini ${ }^{3}$ \\ ${ }^{1}$ Universidade de Rio Verde - FESURV \\ Fazenda Fontes do Saber, s/n \\ 75901-970 - Rio Verde, GO \\ ${ }^{2}$ Estudante de Graduação - FESURV - Rio Verde, GO \\ ${ }^{3}$ Doutoranda em Zootecnia - FCAV - UNESP - Jaboticabal, SP
}

\begin{abstract}
RESUMO
Avaliou-se a qualidade química da cama de frango submetida, por três lotes consecutivos de criação, a diferentes condicionadores químicos. Foram utilizadas 1320 aves, 440 por lote, em delineamento experimental em blocos ao acaso, com cinco tratamentos (Trat. 1 - cama sem tratamento; Trat. 2 - cama tratada com sulfato de alumínio; Trat. 3 - cama tratada com gesso agrícola; Trat. 4 - cama tratada com superfosfato simples e Trat. 5 - cama tratada com cal hidratada) e quatro repetições. As amostras de cama foram coletadas no $42^{\circ}$ dia de utilização. Não houve influência dos condicionadores $(\mathrm{P}>0,05)$ sobre a matéria seca. O sulfato de alumínio reduziu $(\mathrm{P}<0,002)$ o valor de $\mathrm{pH}(7,42 ; 7,07$ e 6,00 , respectivamente no primeiro, segundo e terceiro lotes) e reduziu $(\mathrm{P}<0,05)$ a quantidade de amônia volatilizada $(3,14 ; 1,36$ e $1,79 \mathrm{mg} / 100 \mathrm{~g}$, respectivamente no primeiro, segundo e terceiro lotes), quando comparado aos outros tratamentos. Concluiu-se que o sulfato de alumínio pode ser adicionado à cama de frango para manter $\mathrm{o}$ pH baixo e inibir a volatilização da amônia.
\end{abstract}

Palavras-chave: amônia, cama de frango, condicionador químico, umidade

\begin{abstract}
The chemical quality of poultry litter submitted, for three consecutive flocks, to different chemical conditioners was evaluated. One-thousand-three-hundred and twenty birds, 440 birds per each flock, were allotted to five treatments (Treat. 1 - untreated litter; Treat. 2 - litter treated with aluminum sulfate; Treat. 3 - litter treated with gypsum; Treat. 4 - litter treated with single superphosphate and Treat. 5 litter treated with hydrated lime) in a completely randomized block design with four replicates. Sample litters were collected at 42 days. No influence of the conditioners $(P>0.05)$ on the dry matter results was observed. Aluminum sulfate reduced $(P<0.002) \mathrm{pH}(7.42,7.07$ and 6.00, respectively in the first, second and third flocks) and reduced $(P<0.05)$ the quantity of volatilized ammonia $(3.14,1.36$ and 1.79 $\mathrm{mg} / 100 \mathrm{~g}$, respectively in the first, second and third flocks), in comparison to other treatments. Aluminum sulfate can be added to poultry litter to reduce $\mathrm{pH}$ and to inhibit the ammonia volatilization.
\end{abstract}

Keywords: ammonia, chemical conditioners, moisture, poultry litter

Recebido para publicação em 1 de setembro de 2003

Recebido para publicação, após modificações, em 4 de fevereiro de 2004

*Endereço para correspondência:

Rua Dias da Silva, 46, Recreio dos Bandeirantes - 14883-410 - Jaboticabal, SP

E-mail: cristina@fesurv.br 


\section{INTRODUÇÃO}

Condicionadores químicos são substâncias que adicionadas à cama melhoram sua qualidade física, química e microbiológica, propiciando maior conforto às aves, favorecendo seu desempenho zootécnico e sanitário.

Dentre os condicionadores mais usados, o gesso agrícola é o único que parece interferir no teor de matéria seca da cama, devido à sua alta capacidade de absorver umidade (Wyatt e Goodman, 1992). Sob condições de umidade excessiva a cama pode produzir amônia a partir do metabolismo microbiano sobre os resíduos fecais. Ao desprender-se pode propiciar o aparecimento de lesões respiratórias e oculares de importância econômica. Altos níveis de amônia no ar (60 a 100 ppm) podem ser observados no início da criação, em galpões com reutilização da cama (Gonzáles e Saldanha, 2001).

Vários autores têm avaliado o uso do sulfato de alumínio com o objetivo de reduzir o $\mathrm{pH}$ e a volatilização de amônia da cama de frango (Elkinci et al., 2000; Worley et al., 2000). Burgess et al. (1998) observaram que o sulfato de alumínio reduziu de 7,47 para 4,43 o $\mathrm{pH}$ da cama de frango. Moore et al. (2000) verificaram que sulfato de alumínio reduz significativamente o pH da cama, principalmente nas quatro primeiras semanas do ciclo de criação. A redução do $\mathrm{pH}$ se deve ao fato de o sulfato de alumínio ser um ácido com seis moles de prótons formados para cada mol de sulfato de alumínio dissociado. A aplicação do sulfato de alumínio pode reduzir em até $99 \%$ a volatilização da amônia, utilizando-se doses de $100 \mathrm{~g}$ por $\mathrm{kg}$ de cama de frango (Moore et al., 1995).

O gesso agrícola, com disponibilidade comercial e custo baixo, representa uma alternativa no manejo do esterco avícola. Segundo Glória et al. (1991), é capaz de reduzir a volatilização da amônia em até 49,5\% em 30 dias. Sua utilização, entretanto, tem gerado resultados controversos quanto à umidade, $\mathrm{pH}$ e volatilização de amônia da cama de frango (Wyatt e Goodman, 1992; Neme et al., 2000; Oliveira et al., 2003). Além disso, Sampaio et al. (1999), ao trabalharem com diferentes níveis de gesso em duas formas de aplicação, concluíram que a aplicação parcelada de $30 \%$ de gesso diminuiu a contagem padrão de microrganismos na cama.
O superfosfato simples apresenta ação inibidora da volatilização da amônia da cama de frango (Glória et al., 1991). Segundo Collins, citado pelos mesmos autores, o uso de superfosfato simples é uma das recomendações mais antigas para inibir as perdas de amônia de resíduos orgânicos. Ao ser utilizado nas proporções de 0,4 e $1,0 \mathrm{~kg} / \mathrm{m}^{2}$, o superfosfato simples mostrou-se eficaz na redução da quantidade de amônia volatilizada sendo, porém, efetivo na redução do pH somente até 10 dias de experimento, quando comparado ao tratamento-controle (Reece et al., 1979). Glória et al. (1991), ao utilizarem o superfosfato simples na quantidade de 62,5 a $175 \mathrm{~kg} / \mathrm{t}$ de cama de frango, verificaram que o produto foi eficiente na inibição da volatilização da amônia em até $93 \%$, ao fím de 30 dias.

A cal hidratada tem sido utilizada para melhorar a qualidade da cama de frango. O produto foi avaliado com o propósito de reter nitrogênio na cama de frango por Wildey (1984). O autor constatou que a retenção do nitrogênio durou apenas duas semanas, necessitando de nova aplicação após esse período. Quanto à ação da cal hidratada, Sobih e Dosoky (1990) observaram que ela se mostrou efetiva no controle da emissão de amônia. Moore et al. (1995), ao avaliarem a ação da cal hidratada sobre a cama de frango durante 42 dias, relataram que não houve diferença significativa em relação à cama não tratada. As perdas da amônia por volatilização foram ocasionadas pelo elevado $\mathrm{pH}$. Os autores mencionaram ainda que, ao final do período experimental, houve queda no $\mathrm{pH}$ ocasionada, provavelmente, pela formação do $\mathrm{CaCO}_{3}$.

Ao estudarem a ação do sulfato de cobre (4\%), ácido benzóico (2\%), ácido acético (3\%) e cal hidratada, Sobih e Dosoky (1990) notaram que o sulfato de cobre e a cal hidratada mostraram-se mais efetivos, controlando a emissão de amônia (pela fixação de nitrogênio nos dejetos) durante 21 dias. Os ácidos benzóico e acético controlaram a emissão de amônia somente por 10 e 15 dias, respectivamente.

Este experimento foi realizado com o objetivo de avaliar o efeito do uso de diferentes condicionadores químicos sobre a qualidade da cama de frango em três lotes consecutivos de criação. 


\section{MATERIAL E MÉTODOS}

O experimento foi conduzido no período de maio a outubro de 2002. Foram criados três lotes consecutivos, sendo o primeiro nos meses de maio e junho, o segundo em julho e agosto e o terceiro em setembro e outubro.

Cada lote constou de 440 pintos de um dia de idade, de ambos os sexos, com peso inicial médio de 42,46 $\pm 7,29$ gramas. As aves foram alojadas em galpão de alvenaria dividido em 20 boxes experimentais de $1,85 \mathrm{~m}^{2}$, portanto, em densidade de 12 aves $/ \mathrm{m}^{2}$.

Maravalha foi utilizada como substrato em todos os tratamentos e lotes, na quantidade de $24 \mathrm{~kg} / \mathrm{m}^{2}$, com exceção do tratamento com gesso agrícola, que correspondeu a $40 \%$ do peso total da cama, adicionado somente antes da entrada do primeiro lote. Os outros condicionadores foram adicionados à cama no dia anterior à chegada das aves, em cada lote. Sulfato de alumínio, superfosfato simples e gesso agrícola foram totalmente misturados à cama, a cal hidratada foi misturada somente na camada superficial da cama.

Após a saída do primeiro e segundo lote, o galpão permaneceu aberto. Antes da entrada das aves dos lotes dois e três providenciou-se a retirada dos torrões da superfície das camas que foram revolvidas diariamente, durante sete dias, quando foram ensacadas para a limpeza e desinfecção do galpão. Após a desinfecção, o galpão foi fechado por mais sete dias, quando, então, as camas foram recolocadas nos boxes e novamente tratadas, com exceção das tratadas com gesso agrícola e as do tratamento-controle. No dia seguinte as aves foram colocadas sobre a cama.

O delineamento utilizado foi o de blocos ao acaso, com cinco tratamentos e quatro repetições. Os tratamentos foram: Trat. 1 - cama não tratada; Trat. 2 - cama tratada com sulfato de alumínio (100g/kg) (Moore et al., 2000); Trat. 3 - cama tratada com gesso agrícola na proporção de $40 \%$ do peso total (Bruno et al., 1999), aplicado somente antes do primeiro lote; Trat. 4
- cama tratada com superfosfato simples (30kg/ton) (Glória et. al., 1991); e Trat. 5 - cama tratada com cal hidratada $\left(0,5 \mathrm{~kg} / \mathrm{m}^{2}\right)($ Colmanetti e Benedetti [19..]).

As rações, à base de milho e farelo de soja, foram formuladas de acordo com Rostagno et al. (2000). As aves receberam ração inicial a partir do primeiro dia até 21 dias, ração de crescimento dos 22 aos 35 dias e ração final dos 36 aos 42 dias de idade.

As colheitas de material para análise de matéria seca, $\mathrm{pH}$ e amônia volatilizada foram realizadas em três pontos dentro dos boxes, evitando-se as áreas próximas e embaixo do comedouro e do bebedouro. A análise de matéria seca foi feita de acordo com a metodologia de Silva (2002) e o pH segundo Benabdeljelil e Ayachi (1996). Para determinar a amônia volatilizada foi desenvolvida uma metodologia baseada na adaptação do método proposto por Sampaio et al. (1999), que constou de um recipiente plástico (garrafa PET de refrigerante de 21) com tampa, cortado ao meio, onde foi colocada a amostra de cama $(100 \mathrm{~g})$. Sobre a amostra foi colocado um béquer, com capacidade para $50 \mathrm{ml}$, contendo $10 \mathrm{ml}$ de ácido bórico $2 \%$, cuja função foi captar a amônia volatilizada dentro do recipiente. Após a colocação da amostra e do béquer, o frasco foi vedado com fita adesiva. O frasco coletor possuía um orifício, onde foi colocada uma mangueira de silicone de $5 \mathrm{~mm}$ de diâmetro e $15 \mathrm{~cm}$ de comprimento (Fig. 1).

As amostras de cama foram mantidas dentro do recipiente por 24 horas. Posteriormente, o ácido bórico foi titulado com ácido sulfúrico $0,05 \mathrm{~N}$ e a quantidade de amônia volatilizada determinada utilizando-se a fórmula: $\mathrm{A}=\mathrm{V} \times 0,05 \times 17$, sendo $\mathrm{A}=$ amônia volatilizada $(\mathrm{mg} / 100 \mathrm{~g}$ de amostra), $\mathrm{V}=$ volume de ácido sulfúrico utilizado na titulação $(\mathrm{ml}), 0,05=$ normalidade do ácido sulfúrico e $17=$ peso molecular da amônia.

A análise estatística foi realizada utilizando o sistema de análises estatísticas e genéticas (SAEG) (Sistema..., 1997) e as médias foram comparadas pelo teste Duncan. 


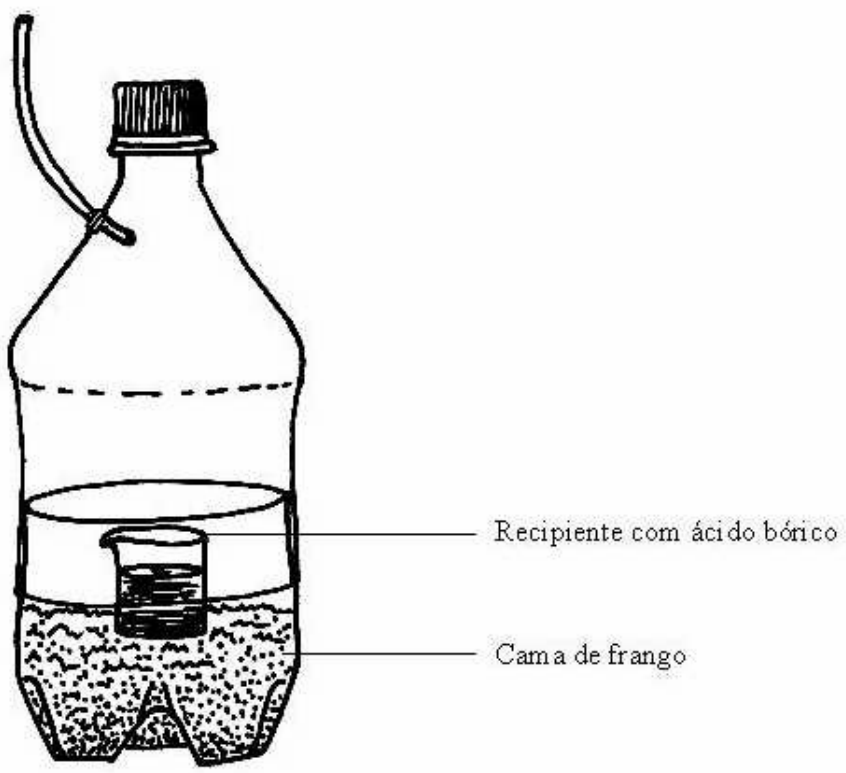

Figura 1. Esquema do método proposto para determinação de amônia volatilizada.

\section{RESULTADOS E DISCUSSÃO}

Os resultados de matéria seca, $\mathrm{pH}$ e amônia volatilizada das camas de frango não tratadas e tratadas com sulfato de alumínio, gesso agrícola, superfosfato simples e cal hidratada encontramse nas Tab. 1, 2 e 3, respectivamente. $\mathrm{O}$ pH e a quantidade de amônia volatilizada foram influenciados pelo uso do sulfato de alumínio, entretanto, não houve efeito sobre o teor de matéria seca da cama ao fim do período experimental, demonstrando que todos os condicionadores utilizados foram efetivos em manter a cama de frango em boas condições em termos de umidade.

Tabela 1. Teor de matéria seca de camas de frango não tratadas e tratadas com diferentes condicionadores

\begin{tabular}{lccc}
\hline \multirow{2}{*}{ Tratamento } & \multicolumn{3}{c}{ Matéria Seca } \\
\cline { 2 - 4 } & $1^{\circ}$ lote & $2^{\circ}$ lote & $3^{\circ}$ lote \\
\hline Cama não tratada & 82,12 & 82,23 & 82,92 \\
Cama + sulfato de alumínio & 82,62 & 82,94 & 83,50 \\
Cama + gesso agrícola & 81,78 & 82,69 & 84,35 \\
Cama + superfosfato simples & 84,49 & 82,03 & 80,53 \\
Cama + cal hidratada & 80,50 & 82,23 & 82,96 \\
Coeficiente de variação (\%) & 2,27 & 1,72 & 2,62 \\
\hline
\end{tabular}

Tabela 2. $\mathrm{pH}$ de camas de frango não tratadas e tratadas com diferentes condicionadores

\begin{tabular}{lccc}
\hline \multirow{2}{*}{ Tratamento } & \multicolumn{3}{c}{$\mathrm{pH}$} \\
\cline { 2 - 4 } & $1^{\circ}$ lote & $2^{\circ}$ lote & $3^{\circ}$ lote \\
\hline Cama não tratada & $8,42 \mathrm{~b}$ & $8,52 \mathrm{a}, \mathrm{b}$ & $7,97 \mathrm{a}$ \\
Cama + sulfato de alumínio & $7,42 \mathrm{c}$ & $7,07 \mathrm{c}$ & $6,00 \mathrm{~b}$ \\
Cama + gesso agrícola & $8,22 \mathrm{~b}, \mathrm{c}$ & $8,12 \mathrm{~b}$ & $7,50 \mathrm{a}$ \\
Cama + superfosfato simples & $7,80 \mathrm{~b}, \mathrm{c}$ & $8,22 \mathrm{a}, \mathrm{b}$ & $7,65 \mathrm{a}$ \\
Cama + cal hidratada & $9,65 \mathrm{a}$ & $8,72 \mathrm{a}$ & $8,27 \mathrm{a}$ \\
Coeficiente de variação (\%) & 6,75 & 3,82 & 7,76 \\
\hline \multicolumn{2}{l}{ Médias seguidas de letras diferentes, nas colunas, diferem } \\
entre si pelo teste Duncan.
\end{tabular}

Tabela 3. Quantidade de amônia volatilizada de camas de frango não tratadas e tratadas com diferentes condicionadores

\begin{tabular}{lccc}
\hline \multirow{2}{*}{ Tratamento } & \multicolumn{3}{c}{$\begin{array}{c}\text { Amônia volatilizada } \\
(\mathrm{mg} / 100 \mathrm{~g})\end{array}$} \\
\cline { 2 - 4 } & $1^{\circ}$ lote & $2^{\circ}$ lote & $3^{\circ}$ lote \\
\hline Cama não tratada & $6,94 \mathrm{a}$ & $8,47 \mathrm{a}$ & $6,12 \mathrm{a}$ \\
Cama + sulfato de alumínio & $3,14 \mathrm{~b}$ & $1,36 \mathrm{~b}$ & $1,79 \mathrm{~b}$ \\
Cama + gesso agrícola & $5,76 \mathrm{a}, \mathrm{b}$ & $7,67 \mathrm{a}$ & $5,92 \mathrm{a}$ \\
Cama + superfosfato simples & $6,22 \mathrm{a}$ & $9,40 \mathrm{a}$ & $5,85 \mathrm{a}$ \\
Cama + cal hidratada & $7,61 \mathrm{a}$ & $8,64 \mathrm{a}$ & $7,72 \mathrm{a}$ \\
Coeficiente de variação $(\%)^{1}$ & 18,55 & 10,96 & 20,12 \\
\hline${ }^{1}$ Coeficiente de variação obtido com médias transformadas \\
(log X). \\
Médias seguidas de letras diferentes, nas colunas, diferem \\
entre si pelo teste Duncan.
\end{tabular}


A umidade da cama relaciona-se a fatores como tipo de dieta, consumo de água, temperatura ambiente, ventilação e, principalmente, tipo de bebedouro usado. $\mathrm{O}$ uso de condicionadores químicos na cama, geralmente, não afeta seu teor de matéria seca, como descrito por McWard e Taylor (2000) (sulfato de alumínio), Ali et al. (2000) (superfosfato), Neme et al. (2000) (gesso agrícola) e Oliveira et al. (2003) (cal hidratada). Entretanto, Wyatt e Goodman (1992), ao estudarem o uso de gesso agrícola na cama de frango, demonstraram que o teor de matéria seca da cama aumentou significativamente de 84,9 para $88 \%$.

O sulfato de alumínio reduziu significativamente $(\mathrm{P}<0,002)$ o $\mathrm{pH}$ das camas ao final de 42 dias de criação em todos os lotes. O pH das outras camas assemelhou-se ao do tratamento-controle, com exceção do obtido no primeiro lote, em que o pH das camas tratadas com cal hidratada foi superior aos demais, por ser substância alcalina. Esperava-se que o superfosfato simples, por ser uma substância ácida, mantivesse o $\mathrm{pH}$ baixo até o fim do experimento. Pode-se inferir que houve perda da eficiência desse produto em manter o $\mathrm{pH}$ baixo até o fim do período experimental, ou que a dosagem tenha sido baixa, ou ainda, que deveria haver uma outra aplicação na segunda fase do ciclo de produção. Com relação ao uso de gesso agrícola e de cal, o elevado $\mathrm{pH}$ já era esperado em todos os lotes. No caso específico da cal hidratada, houve queda não significativa no $\mathrm{pH}$ no segundo e terceiro lotes. Isso é atribuído à formação de carbonato de cálcio nas camas, não suficiente para acidificá-la, mas que interfere na elevação do $\mathrm{pH}$.

Resultados semelhantes foram obtidos por Moore et al. (2000), que testaram a adição de sulfato de alumínio à cama de frango e verificaram redução no $\mathrm{pH}$ das camas em relação ao tratamento-controle. $\mathrm{O} \mathrm{pH}$ obtido por esses autores foram superiores aos do presente experimento, provavelmente, devido ao fato de a cama ser de primeiro lote e não ter sido submetida à aplicações subseqüentes do produto. Moore et al. (1995) estudaram a adição de cal hidratada e não encontraram diferença entre os tratamentos quanto ao pH. Reece et al. (1979) e Ali et al. (2000) também não detectaram diferenças quanto ao $\mathrm{pH}$ de camas tratadas com superfosfato e camas não tratadas, e Sampaio et al. (1999) concluíram que o pH das camas tratadas com 10, 20, 30 e 40\% de gesso agrícola foram semelhantes ao das camas não tratadas.

McWard e Taylor (2000) observaram queda no $\mathrm{pH}$ de camas tratadas com sulfato de alumínio até 21 dias. Aos 42 dias, o pH das camas tratadas era semelhante ao $\mathrm{pH}$ das camas não tratadas (acima de 8,0). Neme et al. (2000) relataram queda no $\mathrm{pH}$ das camas de frango tratadas com gesso agrícola $(8,11 \times 8,96$, respectivamente para camas não tratadas e tratadas) e Oliveira et al. (2003) constataram menor $\mathrm{pH}$ com a adição de gesso agrícola $(6,97)$ comparado à adição de sulfato de alumínio e cal hidratada. Os autores sugeriram que a alta capacidade de absorção de umidade do gesso agrícola reduziu a atividade das bactérias produtoras de amônia, reduzindo o $\mathrm{pH}$ da cama.

O sulfato de alumínio inibiu $(\mathrm{P}<0,05)$ em $54,8 \%$, $83,9 \%$ e $70,8 \%$ a quantidade de amônia volatilizada das camas no $42^{\circ}$ dia no primeiro, segundo e terceiro lotes, respectivamente. Íons $\mathrm{H}^{+}$e $\mathrm{pH}$ abaixo de 7,0 resultam em aumento na proporção $\mathrm{NH}_{3} / \mathrm{NH}_{4}{ }^{+}$, e como o íon amônio não é volátil, há redução das perdas de nitrogênio por volatilização da amônia. À medida que o $\mathrm{pH}$ se eleva, essa razão aumenta, causando maior volatilização. As camas tratadas com sulfato de alumínio apresentaram $\mathrm{pH}$ próximo a 7,0. É provável que o $\mathrm{pH}$ não seja o único fator a influenciar a volatilização da amônia e que os íons alumínio desprendidos na cama interfiram na capacidade de produzir amônia pelas bactérias. Esse mesmo efeito foi observado por McWard e Taylor (2000).

Os resultados são semelhantes aos obtidos por Moore et al. (1996), que utilizaram sulfato de alumínio na quantidade de 65 e $130 \mathrm{~g} / \mathrm{kg}$ de cama e detectaram aumento no teor de $\mathrm{NH}_{4}^{+}$na cama, demonstrando, com isso, que houve redução da amônia volatilizada, e por McWard e Taylor (2000) que verificaram redução na volatilização da amônia de 33,3\% em relação ao tratamentocontrole. Outros autores também não encontraram diferenças com o uso dos demais condicionadores como Moore et al. (1995), ao estudarem o uso da cal hidratada, e Neme et al. (2000), com a adição de gesso agrícola.

Glória et al. (1991) observaram redução na volatilização da amônia na cama de frango tratada com superfosfato simples $(62,5$ a 
$175 \mathrm{~kg} / \mathrm{t})$ e gesso agrícola (50 a $175 \mathrm{~kg} / \mathrm{t})$. A inibição atribuída ao superfosfato simples foi de $58,9 \%$ e ao gesso agrícola, 39,3\%. Da mesma forma, Sampaio et al. (1999), com o uso de gesso agrícola na proporção de $40 \%$ do peso da cama, e Ali et al. (2000), ao utilizarem o superfosfato na quantidade de $0,7 \mathrm{~kg} / \mathrm{m}^{2}$, relataram reduzida volatilização de amônia das camas de frango aos 42 dias.

\section{CONCLUSÕES}

O sulfato de alumínio pode ser adicionado à cama de frango na dosagem de $100 \mathrm{~g} / \mathrm{kg}$ de cama de frango por ser efetivo em manter o $\mathrm{pH}$ da cama baixo e inibir a volatilização da amônia.

\section{REFERÊNCIAS BIBLIOGRÁFICAS}

ALI, M.M; MOUBARAK, S.T.; BADAWY, M.F. et al. Effect of litter treatment on broiler performance and litter quality. Vet. Med. J., v.48, p.309-318, 2000.

BENABDELJELIL, K.; AYACHI, A. Evaluation of alternative litter materials for poultry. J. Appl. Poult. Res., v.5, p.203-209, 1996.

BRUNO, L.D.G.; MORAES, V.M.B.; ARIKI, J. et al. Efeitos da adição de gesso agrícola à cama aviária sobre o desempenho de frangos de corte. Rev. Bras. Zootec., v.28, p.320-325, 1999.

BURGESS, R.P.; CAREY, J.B.; SHAFER, D.J. The impact of $\mathrm{pH}$ on nitrogen retention in laboratory analysis of broiler litter. Poult. Sci., v.77, p.1620$1622,1998$.

COLMANETTI, A.L.; BENEDETTI, E. Utilização da cama de frango como fonte alternativa na alimentação de bovinos: viabilidade econômica de cama de frango. Videira: Perdigão, [19..]. 16p.

ELKINCI, K.; KEENER, H.M.; ELWELL, D.L. Composting short paper fiber with broiler litter and additives. Part I: effects of initial $\mathrm{pH}$ and carbon/nitrogen ratio on ammonia emission. Compost Sci. Util., v.8, p.160-172, 2000.

GLÓRIA, N.A.; BARRETTO, M.C.V.; MORAES, C.J. et al. Avaliação do gesso e de alguns fosfatos como inibidores da volatilização de amônia de estercos. Rev. Bras. Ciên. Solo, v.15, p.297-301, 1991.

GONZÁLES, E.; SALDANHA, E.S.P.B. Os primeiros dias de vida do frango e a produtividade futura. In: CONGRESSO BRASILEIRO DE ZOOTECNIA, 11. 2001, Goiânia. Anais... Goiânia: SBZ, 2001. p.312313. Palestra.

McWARD, G.W.; TAYLOR, D.R. Acidified clay litter amendment. J. Appl. Poult. Res., v.9, p.518-529, 2000.

MOORE, P.A.; DANIEL, T.C.; EDWARDS, D.R. et al. Effect of chemical amendments on ammonia volatilization from poultry litter. J. Environ. Qual., v.24, p.293-300, 1995.

MOORE, P.A.; DANIEL, T.C.; EDWARDS, D.R. et al. Evaluation of chemical amendments to reduce ammonia volatilization from poultry litter. Poult. Sci., v.75, p.315-320, 1996.

MOORE, P.A.; DANIEL, T.C.; EDWARDS, D.R. Reducing phosphorus runoff and inhibiting ammonia loss from poultry manure with aluminum sulfate. $J$. Environ. Qual., v.29, p.29-37, 2000.

NEME, R.; SAKOMURA, N.K.; OLIVEIRA, M.DS. de. Efeito da adição do gesso agrícola em três tipos de cama de aviário na fixação do nitrogênio e desempenho de frangos de corte. Ciênc. Rural, v.30, p.687-692, 2000.

OLIVEIRA, M.C.; ALMEDIA, C.V.; ANDRADE, D.O. et al. Teor de matéria seca, $\mathrm{pH}$ e amônia volatilizada da cama de frango não tratada e tratada com diferentes aditivos. Rev. Bras. Zootec., v. 32, p. 951-954, 2003.

REECE, F.N.; BATES, B.J.; LOTT, B.D. Ammonia control in broiler houses. Poult. Sci., v.58, p.754-755, 1979.

ROSTAGNO, H.S.; ALBINO, L.F.T.; DONZELE, J.L. et al. Tabelas brasileiras para aves e suinos: composição de alimentos e exigências nutricionais. Viçosa: UFV, 2000. 141p.

SAMPAIO, M.A.P.N.; SCHOCKEN-ITURRINO, R.P.; SAMPAIO, A.A. M. et al. Estudo da população microbiana e da liberação de amônia da cama de frango tratada com gesso agrícola. Arq. Bras. Med. Vet. Zootec., v.51, p.559-564, 1999.

SILVA, D.J. Análise de alimentos: métodos químicos e biológicos. 3.ed. Viçosa: UFV, 2002. 235p.

SISTEMA de análises estatísticas e genéticas - SAEG. Viçosa: UFV, 1995. 59p.

SOBIH, M.A.; DOSOKY, R. Fields trials to reduce ammonia content of air in broiler houses. Assiut Vet. J., v.24, p.159-164, 1990.

WILDEY, H. Manage turkey litter to control ammonia. Poult. Dig., v.43, p.257, 1984.

WORLEY, J.W.; CABRERA, M.L.; RISSE, L.M. Reduced levels of alum to amend broiler litter. Appl. Eng. Agric., v.16, p.441-444, 2000.

WYATT, C.L.; GOODMAN, T.N. Research note: the utilization of recycled sheedrock (refined gypsum) as a litter material for broiler houses. Poult. Sci., v.71, p.1572-1576, 1992. 